\title{
HELICOPTER EMS IN CORK: A PARAMEDICINE PERSPECTIVE
}

Shane Knox $\mathrm{PhD}^{1^{*}}$

*president@irishparamedic.ie

\section{OPEN ACCESS ARTICLE}

Recommended Citation: Knox S. Helicopter EMS in Cork: a paramedicine perspective. Irish Journal of Paramedicine. 3(2). Sept 2018. https:// doi.org/10.32378/ijp.v3i2.113

Received: 25 Sep 2018

Accepted: 26 Sep 2018

Published: 26 Sep 2018

Copyright: ๑ 2018, the authors. This is an Open Access article distributed under the terms of the Creative Commons Attribution-Non-CommercialShare Alike 4.0 International licence which permits use, distribution, and reproduction in any medium, provided the original work and any attributes thereof are properly cited, are distributed under the same licence, and that the work is not used for commercial purposes.

\section{cc) (i) (2)}

Funding/support: None declared.

Competing interests: SK is President of the Irish College of Paramedics and an editorial board member of the IJP.

Disclosures: SK is also an Assistant Chief Ambulance Officer with the National Ambulance Service, a member of PHECC and Chair of the Education and Standards Committee within PHECC. Views do not represent any of these or any other organisation. The opinions shared are that of the author representing the Executive of the ICoP. The author's opinion is not in any way related to his employment, employer are associated membership of committees or any organisation other than the Irish College of Paramedics.

Provenance and review: Not commissioned, not peer-reviewed.

Author affiliations

1. Irish College of Paramedics, Ireland.

Acknowledgements:

None

\section{Abstract \\ Introduction}

The intent of this commentary is to provide a paramedicine perspective on the new helicopter EMS service in the Southern region of Ireland, covering mainly Cork and Kerry. The recent discussions regarding the crew composition of the proposed Helicopter Emergency Medical Services (HEMS) in Cork require comment from paramedicine. Whilst we respect the opinion of other professions we feel it is important to provide an Irish perspective on behalf of members of the Irish College of Paramedics - Emergency Medical Technicians (EMTs) Paramedics, and Advanced Paramedics (APs).

Keywords: paramedicine, HEMS, helicopter, flight paramedic 
The recent discussions regarding the crew composition of the proposed Helicopter Emergency Medical Services (HEMS) in Cork require comment from paramedicine. Whilst we respect the opinion of other professions we feel it is important to provide an Irish perspective on behalf of members of the Irish College of Paramedics - Emergency Medical Technicians (EMTs) Paramedics, and Advanced Paramedics (APs).

\section{Regulation and Education}

In Ireland, as with most other developed countries, the provision of pre-hospital care has improved significantly, particularly over the last two decades. The establishment of regulatory bodies (1-3) to provide governance and oversight for pre-hospital providers has been an important step in improving the level of pre-hospital care. Our regulator, the Pre-Hospital Emergency Care Council (PHECC) has introduced national standards for education for pre-hospital practitioners - EMTs, Paramedics and APs comparable to, or exceeding, the standards of paramedicine in other developed countries. New clinical practice guidelines, education and training standards and multiple drugs/medications have all added to the increasing scope of practice. Paramedic education has been provided in conjunction with universities since 1997, well ahead of other jurisdictions and programmes continue to be provided in collaboration with Schools of Medicine at University College Cork, University of Limerick, Royal College of Surgeons Ireland, and University College Dublin. These standards are governed by PHECC and the graduate is then registered and licensed to practice in Ireland, unlike many other healthcare professions and unlike many other jurisdictions where no national registration or regulation occurs.

\section{Crewing Models}

There are varying models of pre-hospital care ranging from paramedic provision of care through the mix of First Aid (4) Basic Life Support (BLS), immediate care, Advanced Life Support (ALS) and the many associated specialist paramedicine grades. This model of paramedic care is typically associated with established systems of pre-hospital care in countries with recognised professional bodies, with or without an associated regulator including Canada, USA, New Zealand, South Africa, Australia, United Kingdom, and Ireland. Depending where you are in the world an ambulance is staffed by varying numbers and differing practitioner qualifications. Discussions on the various types of paramedic/EMS practitioners continues to try to determine which combination of grade provides the most appropriate level of care: ALS (5-7), BLS (8), or a mixed model of crewing?

Countries such as France, Germany, Austria and Malta have physicians who respond to calls in ambulances and response vehicles. In Sweden and the Netherlands, ambulances are staffed by nurses and paramedics. Yet, in Ireland we have not selected this 'Franco-German' model of ambulance response and we have moved away significantly from the nurse deployment model.

\section{Comparison}

Similarly comparison to Australia where helicopters (HEMS) are staffed by doctors is an 'oranges and apples' comparison. Ambulance Victoria have Mobile Intensive Care Paramedics (MICA) and Air Ambulance Paramedics who work on aircraft. There are over 6 million people living in an area of more than 227,000 square kilometres. In 20152016, paramedics in Victoria responded to 589,847 emergency calls: that's one every 55 seconds, and there were an additional 245,944 non-emergency calls. In 2016-2017 Ambulance Victoria responded to 2,128 Helicopter emergency calls.(9) Ambulance Victoria has 4 HEMS and one HEMS Retrieval helicopter. Most Victorian trauma occurs in metropolitan Melbourne but there is a higher per capita incidence of trauma in rural areas. This is related to increased travel distances, greater exposure to roads of lower standard and longer journeys at high speed. The incidence of trauma is most prevalent in rural areas due to increased travel distances and poor road conditions.(10) Victoria is the second largest state in Australia with a population of 6.3 million. Cork, however, has a population of 542,00 and Kerry a population of 147,000.

Flight paramedics are also used internationally - the USA, Canada, South Africa and Australia all utilise paramedics with additional training to allow them to function in 
either helicopters or fixed-wing aircraft as part of a HEMS team, generally without physicians.

\section{Ireland}

Ireland currently has an aeromedical unit based in Athlone. It was established in 2012, is operated by the Air Corps and is staffed by a Defence Forces Emergency Medical Technician and an Advanced Paramedic from the National Ambulance Service. This unit has responded to over 2,500 calls since it was established, with the majority of its calls related to medical emergencies, not trauma. In addition we also have access to four strategically situated Irish Coastguard helicopters staffed by PHECC Registered Paramedics. In total, we have access to six helicopters and an additional HEMS resource in Northern Ireland.

\section{Evidence}

We appreciate the discussions and comments from our colleagues in Emergency Medicine, the medical specialty which has assisted us most in developing into the profession we are today, but we would ask you to consider the context and evidence to support a particular HEMS crewing model. Most emergency calls in Ireland are not related to trauma where indeed a physician could make the greater impact

We have been served well over the last 6 years with the EMT/AP model of HEMS provided by the Air Corps and the National Ambulance Service and there has been no identified need to change this model or evidence to suggest it is not working. We cannot compare HEMS in an Australian state with a population approximately ten times the size of the Cork/Kerry region and an area about the same size as Britain. Paramedics, Emergency Medical Technicians and Advanced Paramedics are all registered by the PreHospital Emergency Care Council and work collaboratively on-the-road and are accustomed to providing care in the pre-hospital environment. Additional skills, relevant to working in a helicopter will be added to the skill set of the selected EMTs/APs

\section{Crew composition}

We believe that the current proposed crew composition of a PHECC Registered, National Ambulance Service Emergency Medical Technician and Advanced Paramedic should be utilised for the new HEMS asset in Cork/Kerry. All data relating to calls (type, management, interventions, receiving facility etc.) should be reviewed at a timely juncture to inform any future potential adjustments to crew composition. We are also of the opinion that PHECC should consider a specific 'Flight Paramedic' programme based on international best-practice and certified by the Regulator to provide a national standard for HEMS paramedicine practitioner - paramedic, EMT and AP.

The discipline of paramedicine is growing and evolving. In years to come paramedics should be involved in more areas of care and not limited to emergency prehospital care. International models of paramedicine include paramedics working in emergency departments, General Practitioner surgeries, in the communities, oil rigs, mining facilities, aircrafts, inter-hospital critical transfers etc.

I personally work with EMTs, paramedics and APs on a regular basis from all services and I have had the opportunity to work with colleagues in other countries. Ireland has a high standard of practitioner comparable to any 'best-practice' international model. I have worked with the staff of HEMS 112 on many occasions and I am always impressed with the level of care all practitioners provide. If practitioners are tasked to different assets and require additional skills, then those additional skills, equipment and medications should be provided to allow them to perform optimally in the HEMS environment.

Finally, we believe the crew of EMT and AP on the HEMS unit in Cork will meet the requirements of patients we serve in the Southern area and that all evidence on this should be reviewed after a period of operation to determine if a different model is required. I personally would be very content to see an experienced Advanced Paramedic and Emergency Medical Technician from HEMS coming towards me at a scene, as either a colleague or indeed a patient. Whilst we may be considered by some as the 'Toyota' and not the 'Rolls Royce' I would like to think we are part of the Toyota family aspiring to be a Lexus, remembering too that Toyota is 'the best built car in the world'! 


\section{References}

1. Health and Care Professions Council (UK) (2016) Registration [online], available: http://hpc-uk.org/aboutregistration/professions/

2. Health Professions Council of South Africa (2016) HPCSA Professional Boards [online], available: http://www.hpcsa.co.za/PBEmergencyCare

3. Pre-Hospital Emergency Care Council (IRL) (2016) [online], available: https:// www.phecc.ie/

4. Tanigawa, K. and Tanaka, K. (2006) 'Emergency medical service systems in Japan: Past, present, and future', Resuscitation, 69(3), 365-370.

5. Eckstein, M., Chan, L., Schneir, A. and Palmer, R. (2000) 'Effect of Prehospital Advanced Life Support on Outcomes of Major Trauma Patients', Journal of Trauma and Acute Care Surgery, 48(4), 643-648.

6. $\quad$ Stiell , I. G., Wells , G. A., Field , B., Spaite , D. W., Nesbitt , L. P., De Maio , V. J., Nichol , G., Cousineau , D., Blackburn , J., Munkley , D., Luinstra-Toohey , L., Campeau , T., Dagnone , E. and Lyver , M. Advanced Cardiac Life Support in Out-of-Hospital Cardiac Arrest'. New England Journal of Medicine, 2004. 351(7), 647-656. https://doi.org/10.1056/NEJMoa040325

7. Jayaraman, S., Sethi, D. and Wong, R. Advanced training in trauma life support for ambulance crews. Cochrane Database Syst Rev. 2014 Aug 21;(8):CD003109. https://doi.org/10.1002/14651858.CD003109.pub3

8. Sanghavi, P., Jena, A. B., Newhouse, J. P. and Zaslavsky, A. M. Outcomes after out-of-hospital cardiac arrest treated by basic vs advanced life support. JAMA Internal Medicine, 2015. 175(2), 196-204. https://doi.org/10.1001/ jamainternmed.2014.5420

9. Ambulance Victoria (2018) 'Ambulance Victoria 2016-2017 Annual Report,' [online], available: https://www.ambulance.vic.gov.au/wp-content/ uploads/2017/10/ambulance-victoria-annual-report-2016-2017.pdf [accessed 26th September 2018]

10. Zalstein, S., Danne, P., Taylor, D., Cameron, P., McLellan, S., Fitzgerald, M., Kossmann, T., Patrick, I., Walker, T., Crameri, J., Bailey, M. and Magilton, G. The Victorian Major Trauma Transfer Study. Injury, 2010. 41(1), 102-109. https://doi.org/10.1016/j.injury.2009.06.020 